\title{
Human Milk Banking and Challenges in Quality Control
}

\author{
B. Vishnu Bhat ${ }^{1} \cdot$ B. Adhisivam ${ }^{1}$
}

Received: 13 January 2018 / Accepted: 23 January 2018 / Published online: 8 February 2018

(C) Dr. K C Chaudhuri Foundation 2018

Every year 27 million babies are born in India of which 3.5 million are preterm and 7.5 million have low birth weight [1]. These neonates constitute a vulnerable cohort in terms of immediate survival and long term neurodevelopmental outcome. Human milk is both immunologically and nutritionally ideal for infants and is especially important for infants born premature in resource limited settings. In 2008, the World Health Organization called for promotion of safe use of donor milk delivered through human milk banks (HMBs) for vulnerable babies. However, scaling up this lifesaving intervention and integrating it with other components of newborn care has been challenging in lower and middle income countries like India. Though the first HMB of India was started in 1989 at Mumbai, the growth of HMBs has not been proportionate to the phenomenal increase in NICUs and preterm deliveries [2]. Nevertheless, there has been renewed interest in this area over the past few years and nearly $50 \mathrm{HMBs}$ are operational in the country today. Though starting a HMB is relatively easy, sustaining voluntary milk donation and maintaining quality of donor human milk (DHM) are arduous tasks but essential. In this context, the research article on utility of dornic acid test for improving quality of DHM by Bhisikar et al. published in this issue of IJP gains importance [3].

The authors have analyzed 477 paired DHM milk samples to correlate the extent of dornic acidity with significant bacterial growth pre pasteurization and to evaluate the effect of pasteurization on dornic acidity. They have noted that $8^{\circ} \mathrm{D}$ had $92 \%$ specificity and $72 \%$ sensitivity in comparison to gold standard microbiological criteria and concluded that dornic acid screening is a simple and feasible test to identify quality of DHM and prediction of bacterial growth prepasteurization

B. Vishnu Bhat

drvishnubhat@yahoo.com

1 Department of Neonatology, Jawaharlal Institute of Postgraduate Medical Education and Research (JIPMER),

Pondicherry 605 006, India
[3]. The good study design and valuable research data generated from the oldest HMB in India has to be appreciated. However, the practical utility of dornic acid test is yet to be established. DHM is like liquid gold and every drop counts. Most HMBs do not practice pre pasteurization testing as the wastage of DHM can be as high as $30 \%$ [4]. Probably this wastage by implementing dornic acid test will outweigh the benefit of this screening test and can potentially increase the expenditure for HMBs. Moreover, $\mathrm{pH}$ measurement seems to be more useful due to certain advantages over the dornic method, such as objectivity, accuracy, standardization, lack of chemical reagents, and the fact that it does not destroy the milk sample [5]. A Spanish study has shown only weak positive correlation between the bacterial growth in DHM and dornic acidity [6].

It is surprising that significant growth was noted in $21 \%$ samples, mostly with coagulase negative staphylococci and gram negative bacteria pre pasteurization. Adhering to strict aseptic techniques during milk collection (whether manual or using pumps) will decrease this contamination. For ensuring safety of DHM, a robust quality assurance mechanism including Hazard Analysis and Critical Control Points (HACCP) system needs to be developed. HMBs should develop their own HACCP in their specific setting to ensure optimal quality and safety. Building successful, integrated HMB systems requires four key steps: (a) establish the fundamental base necessary for quality assurance, and diverse expertise and ownership (for example, staff, space and tools), (b) pursue awareness of and advocacy for breastfeeding, (c) establish a network of HMBs to facilitate auditing, tracking, information sharing and partnerships and (d) develop key protocols to guide operating procedures and the clinical provision of safe DHM [7].

HMBs save lives and should be a key part of any integrated newborn health and nutrition program. They fill the tangible unmet need for DHM as well as cause a ripple effect in the hospital and community leading to improvement in exclusive breastfeeding rates [8]. Our National Health Mission has taken the initiative to establish lactation management centres at secondary and tertiary level public health facilities to universalize 
the availability of breastmilk to all babies in addition to the efforts to promote natural breastfeeding by mothers. This initiative along with Mother's Absolute Affection (MAA) Programme, will result in integration and complementing of breastfeeding promotion activities at community and facility based centres thus improving access to lifesaving human milk for the tiny citizens.

\section{Compliance with Ethical Standards}

Conflict of Interest None.

\section{References}

1. Blencowe H, Cousens S, Oestergaard MZ, et al. National, regional, and worldwide estimates of preterm birth rates in the year 2010 with time trends since 1990 for selected countries: a systematic analysis and implications. Lancet. 2012;379:2162-72.
2. Bharadva K, Tiwari S, Mishra S, et al. Human milk banking guidelines. Indian Pediatr. 2014;51:469-74.

3. Bhisikar S, Mondkar J, Manerkar S, Goel S, D'Dsouza D, Baveja S. Improving quality of banked milk: utility of dornic acid test. Indian J Pediatr 2017. https://doi.org/10.1007/s12098-017-2518-7.

4. Simmer K, Hartmann B. The known and unknowns of human milk banking. Early Hum Dev. 2009;85:701-4.

5. Vázquez-Román S, Escuder-Vieco D, García-Lara NR, et al. Impact of freezing time on dornic acidity in three types of milk: raw donor milk, mother's own milk, and pasteurized donor milk. Breastfeed Med. 2016;11:91-3.

6. Vázquez-Román S, Garcia-Lara NR, Escuder-Vieco D, ChavesSánchez F, De la Cruz-Bertolo J, Pallas-Alonso CR. Determination of dornic acidity as a method to select donor milk in a milk bank. Breastfeed Med. 2013;8:99-104.

7. DeMarchis A, Ballard KI, Mansen KA, Engmann C. Establishing an integrated human milk banking approach to strengthen newborn care. J Perinatol. 2017;37:469-74.

8. Adhisivam B, Vishnu Bhat B, Banupriya N, Poorna R, Plakkal N, Palanivel C. Impact of human milk banking on neonatal mortality, necrotizing enterocolitis, and exclusive breastfeeding - experience from a tertiary care teaching hospital, south India. J Matern Fetal Neonatal Med. 2017;1-4 